\title{
Avaliação de transformação maligna em pacientes portadores de poroceratose de Mibelli de uma mesma família
}

\section{Evaluation of malignant transformation in Mibelli porokeratosis in patients of the same family}

Amanda Maria Menezes Dantas ${ }^{1}$. Thatiana Catunda Torres Mota². Emily Mourão Soares Lopes ${ }^{1}$. Érika Belizário Soares ${ }^{1}$. Karla Linhares Pinto ${ }^{2}$. Alinne Mota Cavalcante' ${ }^{1}$. Maria Genúcia Cunha Matos ${ }^{3}$.

1 Médica residente de Dermatologia, Hospital Universitário Walter Cantídio (HUWC), Fortaleza, Ceará, Brasil. 2 Médica Dermatologista, Hospital Universitário Walter Cantídio (HUWC), Fortaleza, Ceará, Brasil. 3 Médica Dermatologista, Hospital Universitário Walter Cantídio (HUWC), Fortaleza, Ceará, Brasil.

\section{RESUMO}

Introdução: a Poroceratose de Mibelli (PM) é um distúrbio primário da queratinização da epiderme, caracterizado clinicamente por placas com centro atrófico e hiperqueratinização das bordas. A malignização da PM ocorre em cerca de 7\% dos pacientes afetados sendo o carcinoma de células escamosas (CEC) o tumor mais comumente associado. Objetivos: demonstrar casos de transformação maligna em portadores de uma patologia cutânea rara. Resultados: relatamos 2 casos de transformação maligna em portadores de poroceratose de uma mesma família. CASO 1: Paciente do sexo masculino de 53 anos com lesão vegetante no primeiro pododáctilo do pé direito. Foi realizado biópsia da lesão que demonstrou CEC invasivo seguindo-se a amputação de pododáctilo. CASO 2: Paciente de 50 anos, sexo feminino, há 3 meses com lesão pigmentada na região temporal direita, biópsia mostrou um carcinoma de células basais (CBC) e seguiu-se exérese da lesão. Discussão: a PM trata-se de uma doença rara e cronicamente progressiva, decorrente de uma herança autossômica dominante ou de uma forma aleatória. O tratamento da PM deve ser individualizado considerando a estética e a funcionalidade, o potencial de malignização e as preferências do paciente. Em casos de transformação maligna a cirurgia é o tratamento eletivo.

Palavras-chave: Poroceratose. Carcinoma. Dermatopatias.

\begin{abstract}
Introduction: Mibelli's porokeratosis (PM) is a primary disorder of the keratinization of the epidermis, characterized clinically by atrophic plaques with hyperkeratinization of the borders. Malignancies of PM occur in about $7 \%$ of affected patients, with squamous cell carcinoma (SCC) being the most commonly associated tumor. Objectives: To demonstrate cases of malignant transformation in patients with rare skin diseases. Results: this study report 2 cases of malignant transformation in porokeratosis carriers of the same family. CASE 1: A 53-year-old male with a vegetative lesion on the first toe of the right foot. A biopsy of the lesion was performed, which demonstrated invasive SCC following toe-toothed amputation. CASE 2: A 50-year-old female patient, with a pigmented lesion in the right temporal region for 3 months, biopsy showed a BCC (basaloid cell carcinoma) and the lesion was excised. Discussion: PM is a rare and chronically progressive disease due to an autosomal dominant or random inheritance. PM treatment should be individualized considering the aesthetics and functionality, malignant potential and patient preferences. In cases of malignant transformation, surgery is the elective treatment.
\end{abstract}

Keywords: Porokeratosis. Carcinoma. Skin diseases.

Autor correspondente: Amanda Maria Menezes Dantas, Rua Solon Pinheiro 1563, Fátima, Fortaleza, Ceará. CEP: 60050-041. Telefone: +55 85 981679953. E-mail: amanda_mdantas@hotmail.com

Conflito de interesses: Não há qualquer conflito de interesses por parte de qualquer um dos autores.

Recebido em: 03 Abr 2018; Revisado em: 04 Jul 2018; Aceito em: 12 Jul 2018. 


\section{INTRODUÇÃO}

A Poroceratose é um distúrbio primário da queratinização da epiderme, caracterizado clinicamente por placas com centro atrófico e hiperqueratinização das bordas. ${ }^{1,2}$ A principal característica histopatológica é a lamela cornoide, que constitui uma coluna de células paraceratósicas que ocupam pequenas invaginações da epiderme..$^{1-5}$

Poroceratose pode ser classificada em formas localizadas e disseminadas. Classicamente são reconhecidos 5 subtipos clínicos: Poroceratose de Mibelli (PM), Poroceratose linear (PL), Poroceratose superficial disseminada (DSP), Poroceratose actinica superficial (DSAP) e Poroceratose palmo-plantar disseminada (PPPD)., ${ }^{2,3}$

A PM foi originalmente descrita em 1893 por Vittorio Mibelli, sendo a primeira descrição no Brasil em 1934 por Niemayer, trata-se de uma doença rara e cronicamente progressiva, decorrente de uma herança autossômica dominante ou, mais comumente, de uma forma aleatória. PM pode se apresentar como uma única placa ou múltiplas. As lesões normalmente apresentam distribuição unilateral nas extremidades, mas podem ocorrer em outras regiões do corpo (face, lábios, região genital e membranas mucosas).

A PM frequentemente se inicia na infância, especialmente na sua forma hereditária, tendo uma ocorrência maior em homens (razão 2-3:1). Análises genéticas mapearam o gene da PM no cromossomo $3 \mathrm{p} .{ }^{4} \mathrm{O}$ primeiro caso de poroceratose genital foi descrito por Helfman em 1985. Desde então, foram descritos cerca de 30 casos na literatura. ${ }^{5}$

\section{MATERIAIS E MÉTODOS}

Foram incluídos nesse estudo pacientes portadores de Poroceratose provenientes da cidade Fortim, distrito de Pontal do Maceió, todos membros de uma mesma família que apresentassem lesão suspeita de neoplasia. Os pacientes foram encaminhados ao Serviço de Dermatologia do Hospital Universitário Walter Cantídio (HUWC) através de triagem, que constou de anamnese e exame dermatológico. Desenho do estudo:

Trata-se de estudo do tipo observacional transversal, descritivo e de base documental a partir dos dados obtidos da revisão dos prontuários, anamnese e exame clínico dos pacientes com Poroceratose incluídos no estudo.

Os pacientes portadores de poroceratose foram avaliados no primeiro momento em uma consulta de triagem onde foi preenchido formulário no posto de saúde de Pontal do Maceió, Fortim-CE. Os pacientes com lesão suspeita de malignidade foram então encaminhados ao Serviço de Dermatologia do HUWC, onde foram submetidos a anamnese e exame dermatológico e, quando necessário, a biópsias de pele para diagnóstico de neoplasias cutâneas. Em caso de diagnóstico de neoplasias os pacientes foram submetidos a tratamento apropriado.

A coleta dos dados ocorreu através da utilização de um formulário preenchido durante consulta de triagem no posto de saúde de Pontal do Maceió, Fortim-CE, constando com os seguintes dados: idade, sexo, fototipo, renda familiar, escolaridade, comorbidades, antecedentes familiares, tempo de doença, localização da doença, presença de lesão suspeita de neoplasia. Dados adicionais foram obtidos a partir de dados dos prontuários: localização da lesão suspeita, exame dermatológico, histopatológico da lesão suspeita e tratamento realizado.

O projeto foi aprovado pelo Comitê de Ética em Pesquisa (CEP) do HUWC através da Plataforma Brasil, obtendo parecer consubstanciado favorável. Número do Parecer: 2.309.833.

\section{RESULTADOS}

Relata-se 2 casos de transformação maligna em portadores de poroceratose de uma mesma família, de um total de 25 pacientes acometidos com poroceratose. Caso 1: A.E.F., 53 anos, natural e procedente de Fortim-CE, refere surgimento de placas com bordas ceratósicas nos membros inferiores desde os 15 anos de idade. Há cerca de 2 anos evoluiu com surgimento de lesão vegetante com crostas e ulceração no primeiro pododáctilo do pé direito (Figuras 1-2). Seguiu-se a realização de biópsia de pele que se observou a presença de carcinoma espinocelular bem diferenciado invasivo superficial, além disso foi realizada biópsia de pele em uma placa com borda hiperceratósica no dorso do pé que demonstrou epiderme com paraceratose formando coluna cornoide e hipogranulose compatível com Poroceratose de Mibelli (Figura 3). A derme apresenta discreto infiltrado linfomononuclear perivascular.

O paciente foi encaminhado à cirurgia para realizar amputação de pododáctilo, onde seguiu-se a amputação de pododáctilo do pé direito e biópsia de linfonodo sentinela inguinal direito. Histopatológico da lesão mostrou um carcinoma espinocelular moderadamente diferenciado, diâmetro máximo de $3,8 \mathrm{~cm}$, com invasão até tecido ósseo. (Figura 4-5) e histopatológico de linfonodo sentinela mostrou ausência de metástases.

Caso 2: M.A.F, 50 anos, sexo feminino, natural e procedente de Fortim-CE, relata há 3 meses surgimento de lesão pigmentada na região temporal direita, com crescimento progressivo (Figura 6-7), referindo também surgimento de placas com bordas hiperceratósicas no tronco e membros desde a adolescência. Foi realizada exérese de CBC pigmentado na região temporal direita cujo histopatológico mostrou cortes de pele corados no HE (hematoxilina-eosina) camada córnea ortoceratótica, com foco de paraceratose regular (lamela cornoide) e epiderme sem alterações (Figura 8). Em derme neoplasia de células basaloides exibindo paliçada nuclear na periferia e fendas de interface tumor-estroma (Figura 9-10). Nota-se também infiltrado inflamatório linfocitário moderado, perivascular, melanófagos e elastose solar. Derme profunda preservada. Quadro compatível com poroceratose associado a carcinoma basocelular do tipo superficial pigmentado. Margens cirúrgicas livres, Invasão perineural e angiolinfática não detectadas. Estadiamento patológico pT1. 
Figura 1. CEC em placa de Poroceratose de Mibeli.

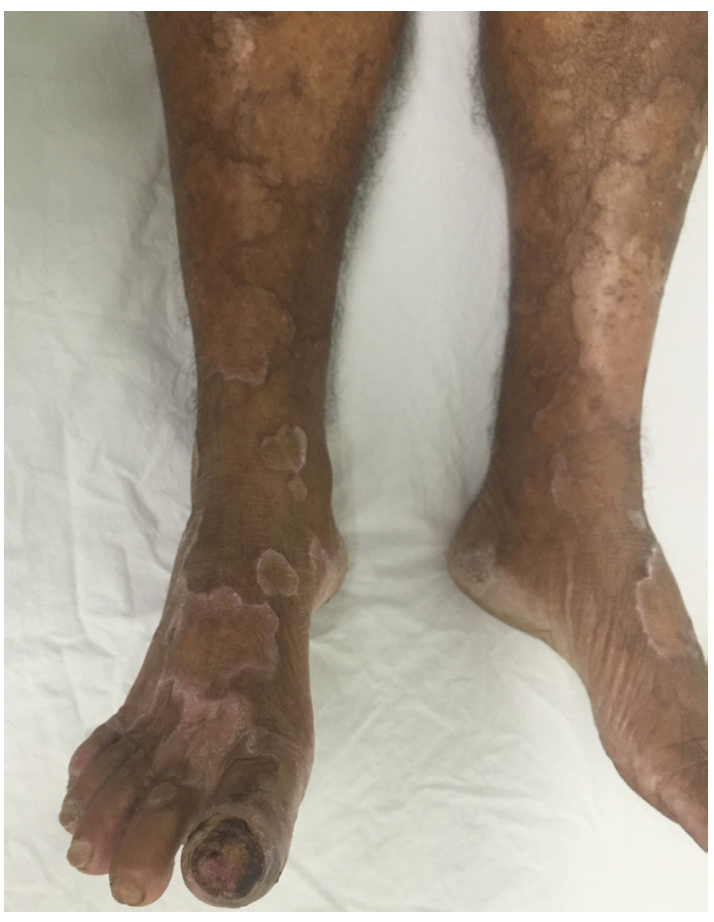

Nota: placas com bordas hiperceratósicas nos membros inferiores com presença de lesão vegetante no primeiro pododáctilo do pé direito.

Figura 2. CEC em hálux de pé direito.

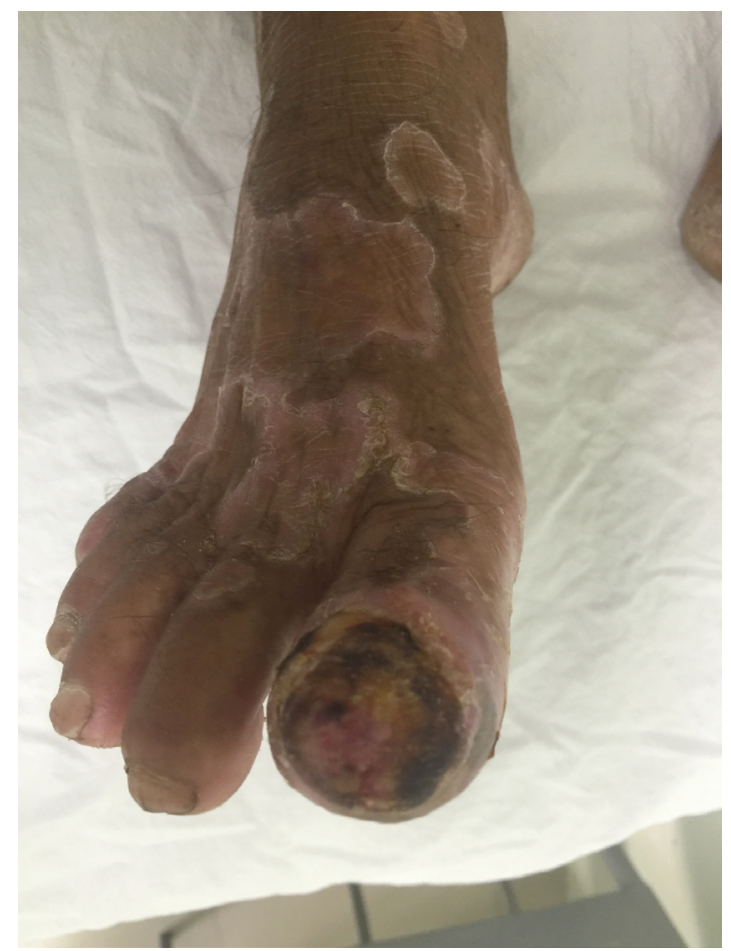

Nota: CEC em placa de poroceratose, imagem em maior aumento mostrando lesão vegetante em hálux e placas com bordas hiperceratósicas.
Figura 3. Poroceratose de Mibelli.

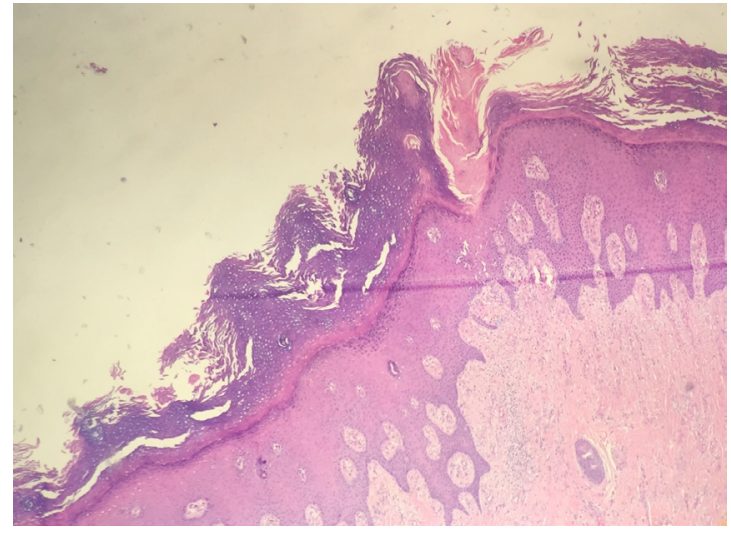

Nota: cortes histológicos em HE mostram epiderme com paraceratose formando coluna cornoide e hipogranulose compatível com Poroceratose de Mibelli.

Figura 4. Carcinoma espinocelular moderadamente diferenciado.

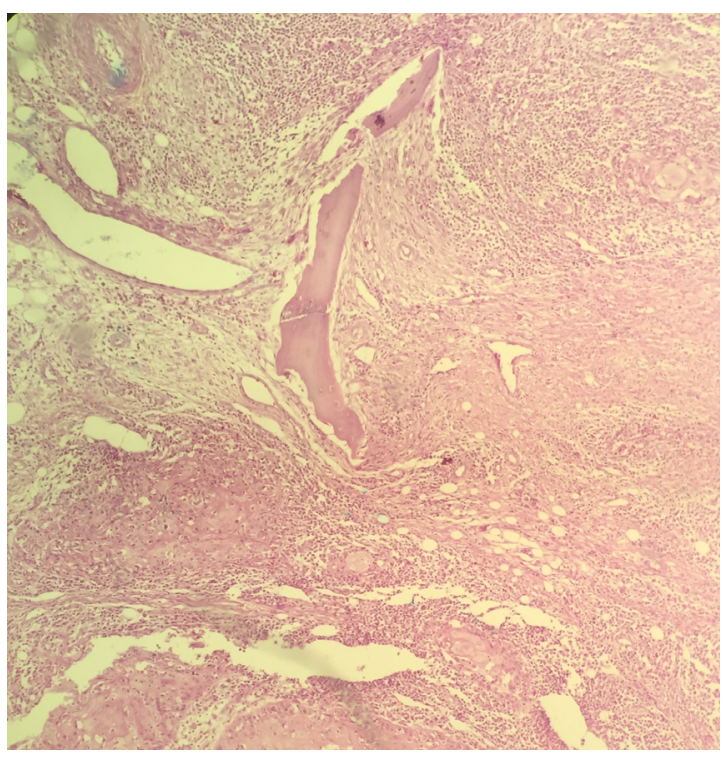

Nota: diâmetro máximo de 3,8 cm, invasão até tecido ósseo.

Figura 5. Produto de amputação de hálux direito.

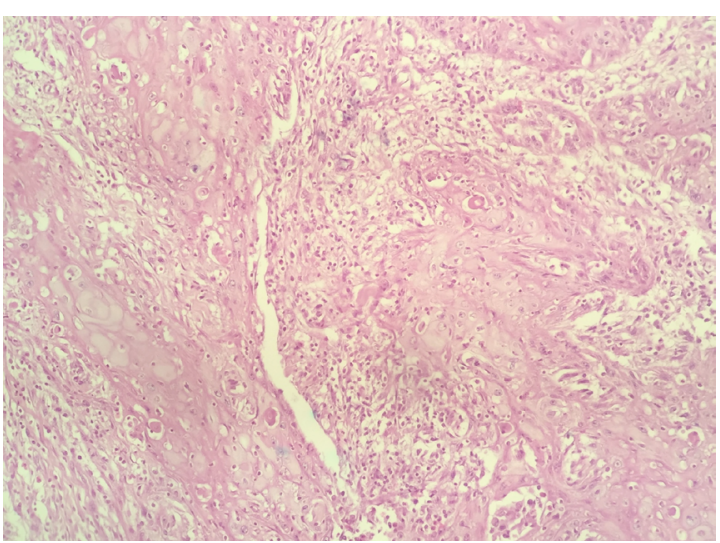

Nota: carcinoma espinocelularmoderadamente diferenciado, diâmetro máximo de $3,8 \mathrm{~cm}$, invasão até tecido ósseo. Invasão perineural e angiolinfática não detectadas. Margens cirúrgicas ósseas e de partes moles livres de neoplasia. 
Figura 6. $\mathrm{CBC}$ pigmentado em placa de Poroceratose na região temporal direita.

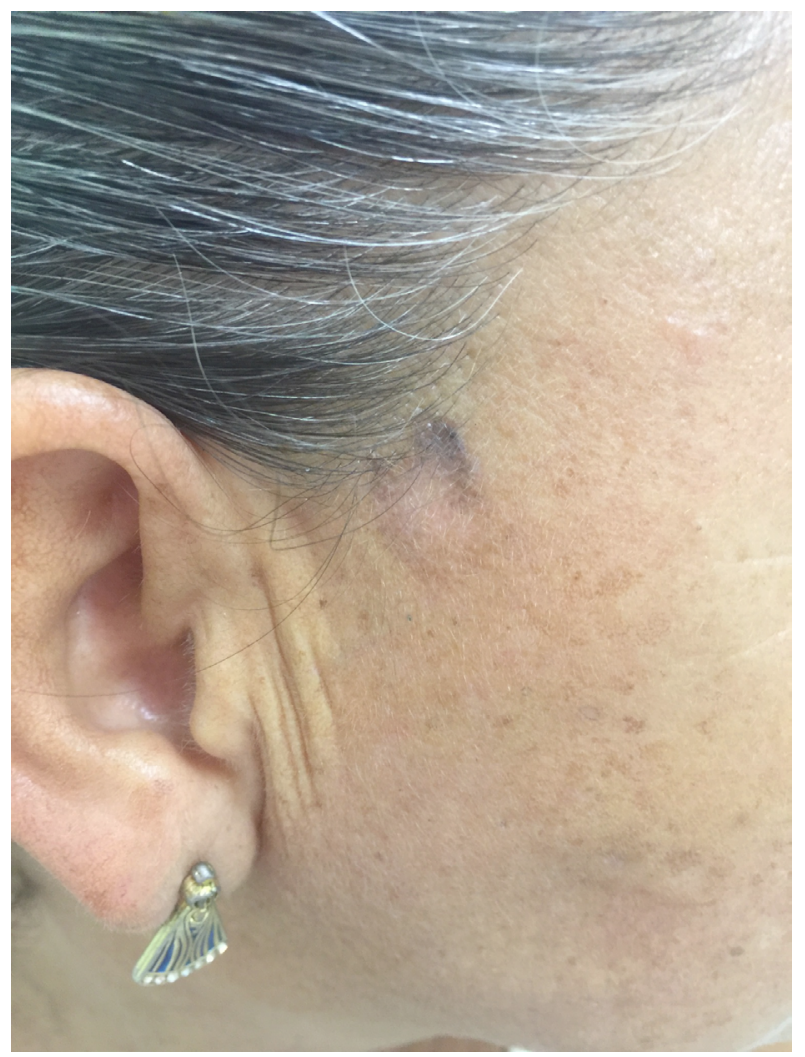

Figura 7. CBC pigmentado a dermatoscopia.

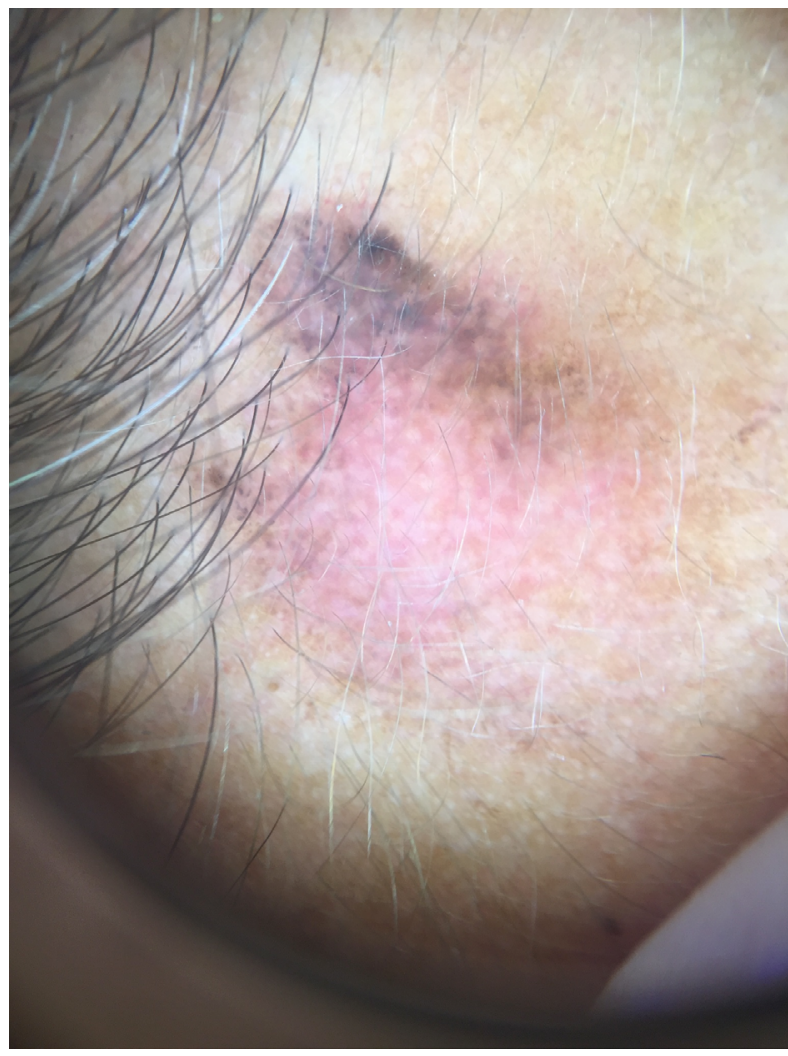

Nota: presença de ninhos ovoides e telangiectasias à dermatoscopia de placa pigmentada com borda ceratósica.
Figura 8. Poroceratose (lamela cornoide em destaque).

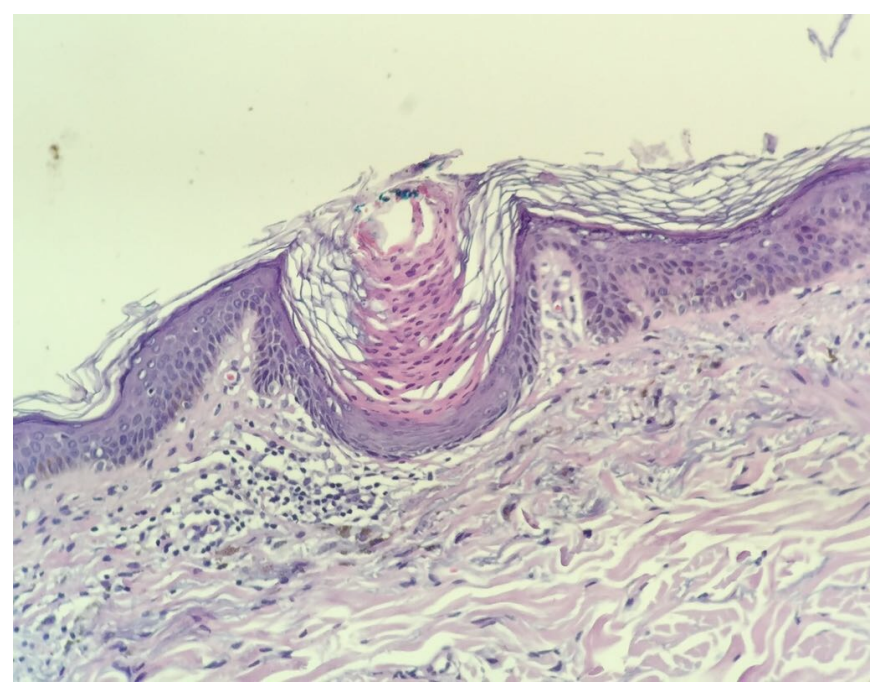

Nota: histopatológico cortes de pele corados no HE mostram camada córnea ortoceratótica, com foco de paraceratose regular (lamela cornoide) associada a hipogranulose focal. Derme papilar com infiltrado inflamatório discreto.

Figura 9. CBC pigmentado associado a poroceratose.

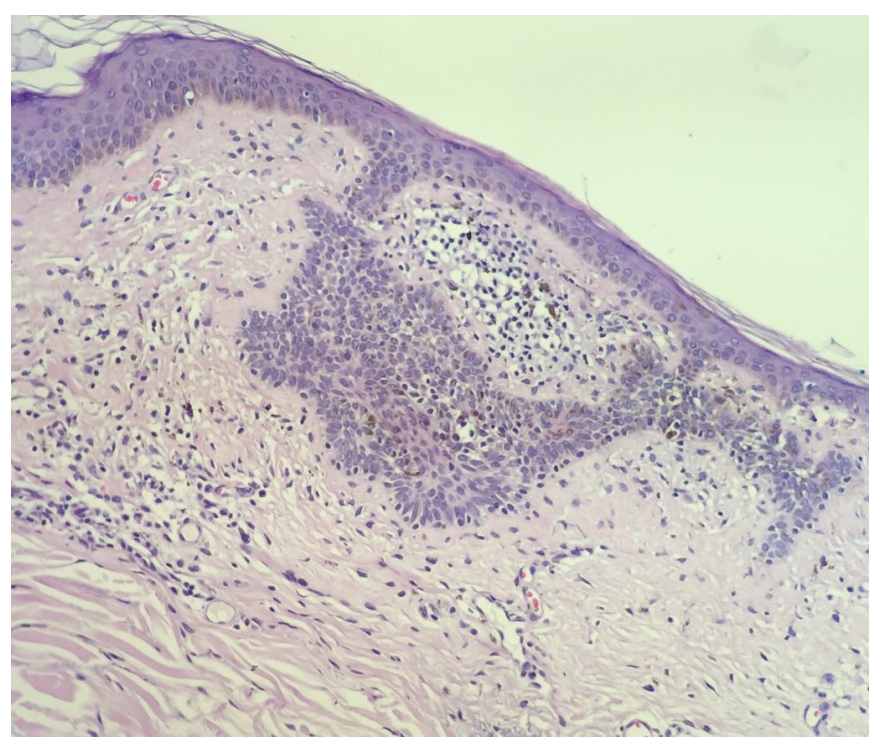

Nota: Histopatológico cortes de pele corados no HE mostram na derme neoplasia de células basaloides exibindo paliçada nuclear na periferia. Nota-se também infiltrado inflamatório linfocitário moderado, perivascular, melanófagos e elastose solar. Derme profunda preservada. Quadro compatível com poroceratose associado a carcinoma basocelular do tipo superficial. 
Figura 10. CBC pigmentado com fendas na interface tumor estroma.

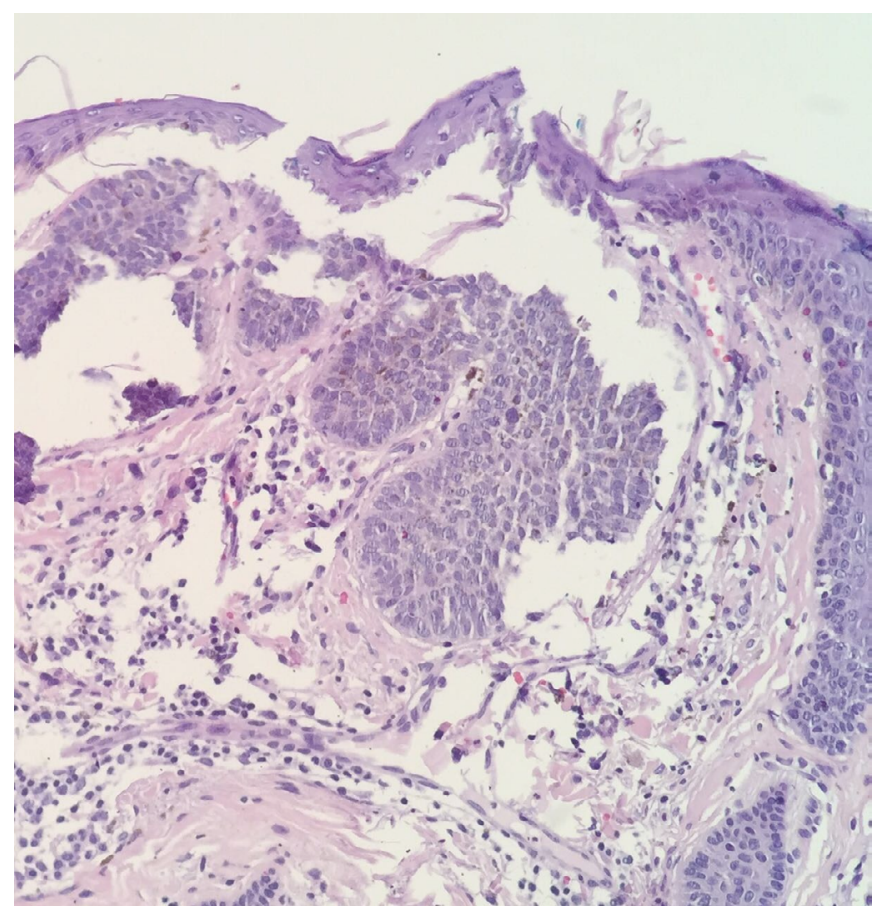

Nota: Histopatológico cortes de pele corados no HE mostram na derme neoplasia de células basalóides exibindo paliçada nuclear na periferia e fendas de interface tumor estroma. Nota-se também infiltrado inflamatório linfocitário moderado, perivascular, melanófagos e elastose solar. Quadro compatível com poroceratose associado a carcinoma basocelular do tipo superficial pigmentado. Margens cirúrgicas livres, invasão perineural e angiolinfática não detectadas. Estadiamento patológico pT1.

\section{DISCUSSÃO}

A malignização da PM foi descrita pela primeira vez por Vigne em 1942 e ocorre em cerca de 7\% dos pacientes afetados. O carcinoma de células escamosas (CEC) é o tumor mais comumente associado, ocorrendo principalmente nas lesões

\section{REFERÊNCIAS}

1. Gutierrez EL, Galarza C, Ramos W, Tello M, de Paz PC, Bobbio L, Barquinero A, Ronceros G, Ortega-Loayza AG. Facial porokeratosis: a series of six patients. Australas J Dermatol. 2010;51:191-4.

2. Chen TJ, Chou YC, Chen CH, Kuo TT, Hong HS. Genital porokeratosis: a series of 10 patients and review of the literature. $\mathrm{Br}$ J Dermatol. 2006;155(2):325-9.

3. Bozdag KE, Bicakci H, Ermete M. Giant porokeratosis. Int J Dermatol. 2004;43(7):518-20.

4. Luan J, Niu Z, Zhang J, Crosby ME, Zhang Z, Chu X, et al. A novel locus for disseminated superficial actinic porokeratosis maps to chromosome 16q24.1-24.3. Hum Genet. 2011;129(3):329-34.

5. Helfman RJ, Poulos EG. Reticulated porokeratosis. A unique variant of porokeratosis. Arch Dermatol. 1985;121(12):1542-3. maiores e lineares. A associação com a doença de Bowen e carcinoma de células basais $(\mathrm{CBC})$ também é descrita. ${ }^{6-10}$ Esse potencial oncogênico pode ser resultante de um aumento da expressão de p53 nos queratinócitos próximos à lamela cornoide. ${ }^{6,11}$ Nos casos relatados observamos 2 exemplos de transformação maligna em portadores de poroceratose, no primeiro caso um CEC invasivo e no segundo caso um CBC pigmentado, nas placas de poroceratose. A associação de lamelas cornoides a alterações displásicas locais sugere que esta dermatose pode resultar da expansão localizada e clonal de queratócitos anormais. Os fatores contribuintes para essa proliferação clonal podem ser intrínsecos (instabilidade cromossomo $3 p$ ) ou extrínsecos (tais como imunossupressão, exposição à radiação ultravioleta, agentes infecciosos, trauma mecânico e drogas). ${ }^{12} \mathrm{O}$ tratamento da PM deve ser individualizado considerando a estética e a funcionalidade, o potencial de malignização e as preferências do paciente. Nos casos de transformação maligna a cirurgia é o tratamento eletivo. A fotoproteção constitui peça fundamental na prevenção de transformação maligna nos pacientes afetados. Outras abordagens possíveis descritas incluem a crioterapia (nitrogênio líquido), laser de CO2, dermoabrasão, retinoides orais e tópicos, análogos tópicos de vitamina D3, agentes queratolíticos, corticoides tópicos e intralesionais, 5 -fluorouracil tópico e mais recentemente imiquimod a 5\%, diclofenaco tópico a $3 \%$ e terapia fotodinâmica. ${ }^{4,6,12,13} \mathrm{Em}$ ambos os casos relatados foi optado por excisão cirúrgica com margens amplas. No primeiro caso, pela presença de CEC com invasão até estruturas ósseas, foi optado pela amputação de pododáctilo e seguiu-se o estudo de linfonodo sentinela que se revelou negativa. No segundo caso foi feita excisão cirúrgica também com margens amplas e não houve necessidade de nova abordagem. A importância dos casos relatados encontra-se na raridade dessa patologia cutânea bem como na presença de transformação maligna, nesses pacientes moradores de uma comunidade de pescadores do interior do Ceará cronicamente exposta ao sol sem uso de fotoproteção adequada.

6. Laureano A, Macias VC, Pacheco FA; Poroqueratose de mibelli um caso clínico. Revista SPDV. 2012;70:209-12.

7. Lee HR, Han TY, Son SJ, Lee JH. Squamous cell carcinoma developing within lesions of disseminated superficial actinic porokeratosis. Ann Dermatol. 2011;23(4):536-8.

8. Li JH, Yang ZH, Li B, Chen HD. Squamous cell carcinoma arising from giant porokeratosis. Dermatol Surg. 2011;37(6):855-7.

9. Scola N, Skrygan M, Wieland U, Kreuter A, Gambichler T. Altered gene expression in squamous cell carcinoma arising from congenital unilateral linear porokeratosis. Clin Exp Dermatol. 2012;37(7):781-5.

10. Vivas AC, Maderal AD, Kirsner RS. Giant ulcerating squamous cell carcinoma arising from linear porokeratosis: a case study. Ostomy Wound Manage. 2012;58(11):18-20. 
11. Dal Santo Francisco B, Salamí OA, Santos RB, Jorge MA, Gonzaga HF. Poroqueratose de Mibelli: uma condição que pode evoluir para neoplasia maligna. Rev Bras Med. 2011;68:7-9.

12. Zhang SQ, Jiang T, Li M, Zhang X, Ren YQ, Wei SC, et al. Exome sequencing identifies MVK mutations in disseminated superficial actinic porokeratosis. Nat Genet. 2012;44(10):1156-60.

13. Sertznig P, von Felbert V, Megahed M. Porokeratosis: present concepts. J Eur Acad Dermatol Venereol. 2012;26(4):404-12.

\section{Como citar:}

Dantas AM, Mota TC, Lopes EM, Soares EB, Pinto KL, Cavalcante AM, et al. Avaliação de transformação maligna em pacientes portadores de poroceratose de Mibelli de uma mesma família. Rev Med UFC. 2019 jan-mar;59(1):61-66. 